\title{
Cryptic species of Didymobothrium rudolphii (Cestoda: Spathebothriidea) from the sand sole, Solea lascaris, off the Portuguese coast, with an analysis of their molecules, morphology, ultrastructure and phylogeny
}

\author{
J. F. MARQUES ${ }^{1 *}$, M. J. SANTOS ${ }^{2}$, D. I. GIBSON ${ }^{3}$, H. N. CABRAL ${ }^{1}$ and P. D. OLSON ${ }^{3}$ \\ ${ }^{1}$ Universidade de Lisboa, Faculdade de Ciências, Instituto de Oceanografia, Campo Grande, 1749-016 Lisboa, Portugal \\ ${ }^{2}$ Universidade do Porto, Faculdade de Ciências, Departamento de Zoologia e Antropologia, Praça Gomes Teixeira, 4099-002 \\ Porto and CIMAR/CIIMAR - Centro Interdisciplinar de Investigação Marinha e Ambiental, Rua dos Bragas, 177, 4050-123 \\ Porto, Portugal \\ ${ }^{3}$ Department of Zoology, Natural History Museum, Cromwell Road, London SW7 5BD, UK
}

(Received 3 November 2006; revised 9 Ganuary 2007; accepted 10 Fanuary 2007; first published online 28 February 2007)

\section{SUMMARY}

Didymobothrium rudolphii (Cestoda: Spathebothriidea) was collected seasonally from the sand sole, Solea lascaris, off the northern, central and southern areas of the Portuguese coast. Morphological and molecular analyses were conducted in order to examine the possible existence of cryptic species and to facilitate the circumscription of their morphological boundaries. Data were compared between D. rudolphii specimens from each of the 3 geographical areas and 4 seasons, and principal components analysis of 18 morphological characters was used to detect differences. Two distinct genotypes were present with sequence divergences of $1.9 \%$ and $2 \cdot 1 \%$ in the large subunit (lsrDNA) and second internal transcribed spacer (ITS-2) of ribosomal DNA (rDNA), respectively. The less common 'central' genotype was present only off the central area from summer to winter, whereas the 'common' genotype was present throughout the year off the northern and southern areas, but only during spring in the central area. No sequence variation was found within each genotype. The presence of 2 distinct genetic entities was supported by morphological analyses, which showed the 'central' genotype specimens to be more slender and elongate, although morphometric ranges overlapped considerably for most characters. Molecular phylogenetic analysis of 4 of the 5 known genera of the Spathebothriidea showed Spathebothrium to be the earliest branching lineage and the 2 genotypes of Didymobothrium formed a sister group to Cyathocephalus. The concordance of genetic differences with variation in host diet according to season and locality could account for sympatric speciation occurring in the central region of the Portuguese coast.

Key words: Didymobothrium, Spathebothriidea, large-subunit rDNA, ITS-2, cryptic speciation, systematics, Solea lascaris, Bothrimonus, Cyathocephalus, Diplocotyle, Spathebothrium, Portuguese coast.

\section{INTRODUCTION}

Tapeworms of the order Spathebothriidea are unique in exhibiting serially repeated reproductive organs without the accompanying segmentation that is the hallmark of the Cestoda. They comprise only 5 genera, are widely but disjunctively spread across the northern hemisphere, and have a similarly disparate pattern of host associations, occurring in a small number of marine, euryhaline and freshwater teleosts and chondrosteans (Gibson, 1994). In addition, ovigerous adults of both freshwater and marine forms are known to develop in Amphipoda, circumventing the necessity of a vertebrate final

* Corresponding author: Universidade de Lisboa, Faculdade de Ciências, Instituto de Oceanografia, Campo Grande, 1749-016 Lisboa, Portugal. Tel: + 351217500 826. Fax: +351 217500 207. E-mail: jimarques@fc.ul.pt host in the life-cycle (Gibson and Valtonen, 1983; Protasova and Roytman, 1995 ; Davydov et al. 1997; Okaka, 2000; Mackiewicz, 2003; Poddubnaya et al. 2003, 2005). Taken together, such characteristics suggest that the Spathebothriidea is a relict group of tapeworms whose extant forms represent refugial lineages of a clade that was once more diverse. Moreover, molecular phylogenetic studies indicate that the Spathebothriidea does indeed form a basal lineage of the Eucestoda (possibly the sister group to the other Eucestoda; for a review see Olson and Tkach, 2005), from which it is inferred that they exhibit the ancestral condition of the unsegmented Cestodaria (i.e. Amphilinidea and Gyrocotylidea) in combination with the derived condition of having proglottides (i.e. exhibiting serially-repeated reproductive organs). They may therefore represent the key step in the evolution of the reproductive strategy that now characterizes the vast majority of 
cestodes. Nevertheless, they are rarely reported and remain largely unknown in most aspects of their biology.

The systematics and affinities of the Spathebothriidea with other cestode orders have been controversial (e.g. Burt and Sandeman, 1969; Gibson, 1994; Brunanska et al. 2005; Poddubnaya et al. 2005), as has the validity of 3 of the 5 genera: Bothrimonus Duvernoy, 1842, Diplocotyle Krabbe, 1874 and Didymobothrium Nybelin, 1922. Burt and Sandeman (1969) presented a detailed review of the systematics and morphology of these genera, concluding that the differences used to separate them were not valid and that Diplocotyle and Didymobothrium should therefore be regarded as junior synonyms of Bothrimonus. Gibson (1994), following Nybelin (1922), differentiated Bothrimonus from the other two genera by the lack of a septum dividing the lumina of the bothridia, and Diplocotyle and Didymobothrium from one another by the arrangement of the genital pores: ventral in the former and irregularly alternating in the latter. Nevertheless, at about the same time, Protasova and Roytman (1995) considered Didymobothrium a nomen dubium, suggesting that $D$. rudolphii (Monticelli, 1890) Nybelin, 1922 might prove to be a synonym of Diplocotyle olvikii Krabbe, 1874. Detailed morphological studies have been conducted on Diplocotyle nylandica (Schneider, 1902) (see MacKinnon and Burt, 1984) and D. olvikii (see Brunanska et al. 2005; Poddubnaya et al. 2005), but Bothrimonus spp. (sensu stricto) and Didymobothrium rudolphii remain poorly known, only the ultrastructure of the vitelline system of the latter having been studied in detail by Poddubnaya et al. (2006).

In a parasitological survey of the soles Solea lascaris (Risso, 1810) and S. impar Bennett, 1831 (Pisces, Pleuronectiformes) conducted along the northeast Atlantic coast and in the Mediterranean (including a sampling site near Lisbon, on the Portuguese coast), Renaud and Gabrion (1988) found these species to be infected with what they considered Bothrimonus nylandicus, following the work of Burt and Sandeman (1969). Using allozyme electrophoresis, they demonstrated 2 cryptic species occurring in both the Atlantic and the Mediterranean. Whereas one of the cryptic species was found throughout the year, the other first appeared in spring and was absent by the end of the summer. To account for this, the authors' formulated a number of hypotheses regarding the longevity of the different 'species' and the potential for different intermediate host specificity driving speciation.

Off the coast of Portugal, D. rudolphii is commonly found infecting S. lascaris throughout the year, enabling continual sampling of the parasite populations from this commercially important host species. Although Renaud and Gabrion (1988) reported

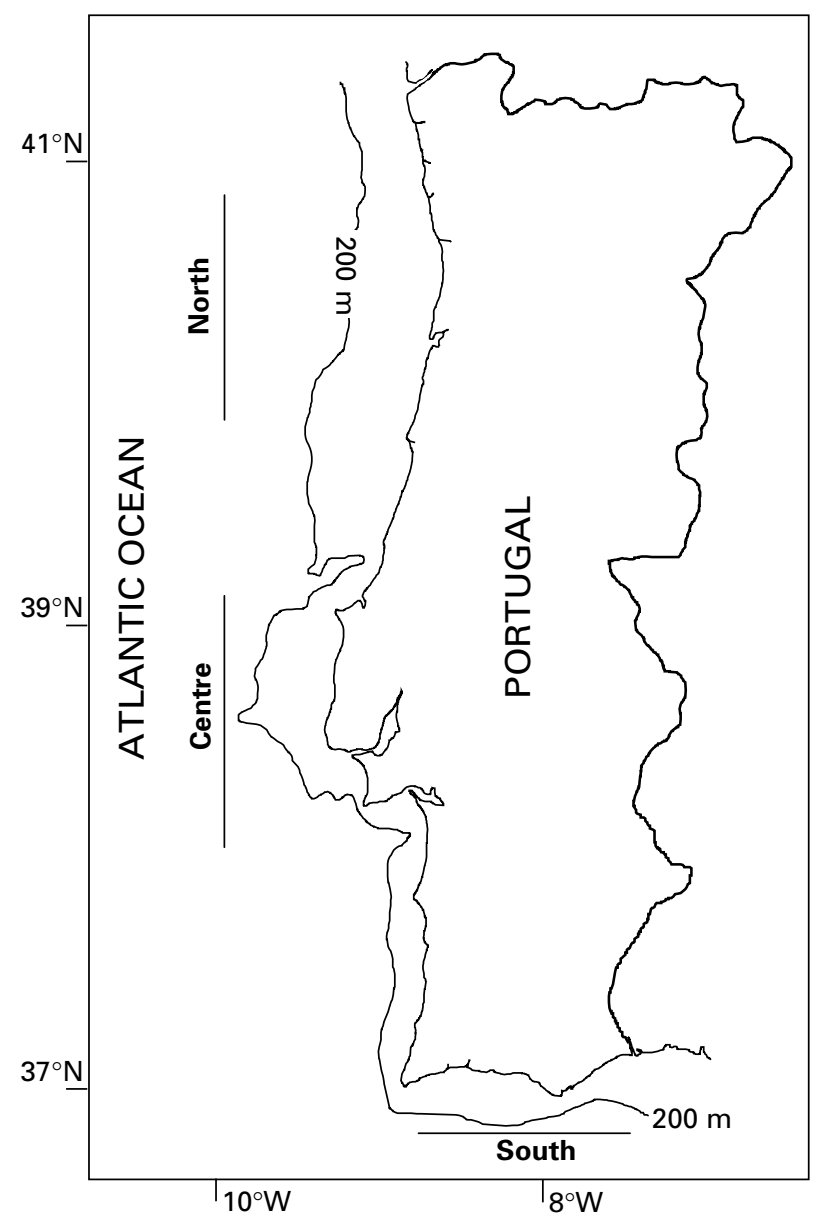

Fig. 1. Sampling areas off the Portuguese coast.

D. rudolphii (as B. nylandicus) to infect $S$. impar off the Portuguese coast, the taxonomic validity of this host is currently in question (Infante et al. 2004), and no specimen sampled in the present study corresponded to the description of $S$. impar. In order to investigate further the presence of cryptic species and to attempt to circumscribe the morphometric and molecular variation exhibited by these entities, parasites were collected seasonally from the northern, central and southern areas off the Portuguese coast (Fig. 1). This material also provided an opportunity to study their morphology in detail for the first time, including ultrastructural and histological features, thus significantly augmenting previous accounts published more than 80 years ago (i.e. Monticelli, 1890, 1892; Nybelin, 1922).

\section{MATERIALS AND METHODS}

\section{Specimen collection and vouchers}

During 2003, 480 specimens of the sand sole, Solea lascaris, were obtained from commercial fishing vessels operating off the northern $(n=158)$, central $(n=169)$ and southern $(n=153)$ areas of the Portuguese coast (Fig. 1) and examined for the 
presence of D. rudolphii. Cestode specimens were fixed in 10\% neutral-buffered formalin, $2 \cdot 5 \%$ phosphate-buffered glutaraldehyde or $100 \%$ analytical grade ethanol, depending on the technique to be used subsequently. The stomach contents of the fish were also examined, in order to gain insights into host feeding ecology and its relationship to infection patterns. Voucher specimens, including whole-mounted and sectioned material used for morphological study, were deposited in the Museu Nacional de História Natural (Museu Bocage), Lisbon (MNHN MB8-19), and wholemounted, partial specimens of 12 of the 24 samples used for molecular analysis were deposited in the Natural History Museum, London (BMNH 2006.10.4.9-20).

\section{Molecular analyses}

Eight individuals from each of the 3 sampling areas ( 2 per season; 24 in total) were fixed in pure ethanol for molecular analysis. Ethanol was replaced with Tris-ethylenediamine tetracetic acid (EDTA) buffer ( $\mathrm{pH} 8 \cdot 0$ ) by soaking overnight, and genomic DNA was extracted using a Qiagen DNeasy ${ }^{\text {TM }}$ tissue kit, with modifications as described by Agustí et al. (2005). Two nuclear ribosomal regions were characterized: the large-subunit (lsrDNA) which has proven to be informative for both phylogenetic and diagnostic studies of the Cestoda (e.g. Brickle et al. 2001; Olson et al. 2001; Reyda and Olson, 2003; Agustí et al. 2005; Aznar et al. 2007) and the second internal transcribed spacer (ITS-2) which has been commonly used for investigating inter- and intraspecific variation in flatworms (e.g. Verneau et al. 1997; Zehnder and de Chambrier, 2000; Olson et al. 2002; see Olson and Tkach, 2005 and Nolan and Cribb, 2005). Partial lsrDNA (D1-D3; 1400 bp) and complete ITS-2 ( $600 \mathrm{bp})$ genes were amplified by polymerase chain reaction (PCR) using oligonucleotide primers LSU5 (5' TAG GTC GAC CCG CTG AAY TTA AGC 3') +1200R (5' GCA TAG TTC ACC ATC TTT CGG 3'), and ITS2.3S (5' GGT ACC GGT GGA TCA CGT GGC TAG TG 3') + ITS2.2 (5' CCT GGT TAG TTT CTT TTC CTC CGC 3'), respectively. Cycle sequencing was performed bidirectionally using the PCR primers and internal primers $300 \mathrm{~F}$ (5' CAA GTA CCG TGA GGG AAA GT'T 3') and ECD2 (5' C'TT GGT CCG TGT TTC AAG ACG GG 3') in the case of the 1srDNA. Contiguous sequences were assembled and edited using Sequencher ${ }^{\mathrm{TM}}$ (GeneCodes Corp.), screened for contamination via BLASTn (McGinnis and Madden, 2004) and deposited in GenBank under Accession numbers EF042920- EF042965.

To facilitate comparative sequence and phylogenetic analyses, collection and/or sequencing of additional spathebothriidean taxa was carried out as follows: a gravid (progenetic) specimen of Diplocotyle olvikii was collected from Gammarus sp. (Amphipoda) at St Andrews, Scotland and both the 1srDNA and ITS-2 characterized; the ITS-2 was also characterized for Spathebothrium simplex Linton, 1922 and Cyathocephalus truncatus (Pallas, 1781) in order to complement lsrDNA sequences characterized previously for these taxa (see Olson et al. 2001).

In order to maximize the number of alignable characters, and thus provide the best estimates of relative divergences from the available sequences, data sets were constructed for the 1srDNA and ITS-2 representing only the spathebothriidean taxa and were thus analysed phylogenetically as unrooted networks. In addition, a third data set based on lsrDNA was constructed that included sequences representing 2 gyrocotylidean outgroups in order to root the spathebothriidean clade; of the $\sim 1400 \mathrm{bp}$ of lsrDNA characterized, only $881(\sim 63 \%)$ were alignable together with the gyrocotylidean sequences, whereas $1275 \quad(\sim 91 \%)$ were alignable when considering only the spathebothriidean taxa. One representative sequence of each of the 2 distinct Didymobothrium genotypes found were used in all analyses. Alignments were made by eye using the program MacClade 4.08 (Maddison and Maddison, 2005). Comparative and bootstrap analyses were performed using PAUP* 4.0b10 (Swofford, 2001), and phylogenetic affinities were estimated by Bayesian inference using MrBayes 3.1.2 (Ronquist and Huelsenbeck, 2003). Nucleotide substitution models were estimated for each data set individually using MrModeltest 1.1b (Nylander, 2004), a simplified version of ModelTest (Posada and Crandall, 1998) and a general time-reversible model of nucleotide substitution incorporating gammadistributed among site rate variation $(G T R+G$ for the ITS-2 data) or invariant sites $(G T R+I$ for the lsrDNA data), or both (GTR $+\mathrm{I}+\mathrm{G}$ for the lsrDNA data including the gyrocotylidean outgroup taxa), was specified and the analyses run over 0.5 million generations, sampling topologies every 100 th generation. Other program parameters were as specified by Olson et al. (2003). Consensus trees were constructed using the 'sumt' command with 'burnin' $=20$ and 'contype' = allcompat.

\section{Morphometric analyses}

For comparative morphometric analysis, 60 complete individuals ( 5 per season per locality) presenting different degrees of maturation were fixed in $70 \%$ ethanol, stained with iron acetocarmine (following Georgiev et al. 1986), dehydrated in an ethanol series, cleared with clove oil, mounted in Canada balsam and observed using light microscopy. Specimens were classified as 'immature' (without fully-formed reproductive organs), 'mature' (with 
fully-formed reproductive organs, but without eggs) or 'gravid' (with fully-formed reproductive organs and with eggs) following Poddubnaya et al. (2003). Sixteen continuous and 2 meristic characters (Table 2) were measured using a compound microscope linked to image analysis software (Axiovision 3.1). Characters were chosen based on their diagnostic value following previous studies (Burt and Sandeman, 1969; Gibson, 1994; Pertierra, 2002; Hanzelová et al. 2005) and the original description (Monticelli, 1890). Since measurements of the reproductive organs vary according to the width of the individual, the width of the uterus, ovary and vitellarium were divided by the total width of the body in order to establish a ratio, expressed as a percentage of the body width, which could be compared meaningfully among the specimens. The number of testes was determined in mature proglottides only, since they degenerate as the worms become gravid. Unless otherwise indicated, measurements are presented in micrometres $(\mu \mathrm{m})$ and given in the text as the mean or as a range. Only complete and either mature or gravid specimens were considered in the statistical analyses, and an average of the reproductive characters from 3 proglottides per individual was made. Following the results of genetic analyses, the morphometric data were pooled separately between the specimens originating in the north and south during all seasons, and for the central area from winter to summer. Metric data from the 2 genotypes (see molecular results) were compared with each other as well as with those published for Diplocotyle and 'Bothrimonus' spp. sensu lato (Table 2). Differences between measurements of the 2 genotypes were tested at the significance level of 0.05 through an independent samples $t$-test (continuous variables) or Mann-Whitney (meristic variables) using the software package SPSS 13.0 (SPSS Inc., 2004).

Principal component analysis (PCA) was conducted in CANOCO 4.5 (ter Braak and Smilauer, 2002) to determine the multivariate relationship among the 16 continuous morphometric variables and to identify the most important of these for distinguishing potentially cryptic species. In order to have a better understanding of the variables influencing morphological variation, specimens from the central area collected during spring (which, according to the molecular results, exhibited the 'common' genotype) were excluded from this analysis. Variables showing the highest influence on the pattern found were tested for significant differences, at a level of $0 \cdot 05$, according to locality or season using the KruskalWallis test carried out in SPSS 13.0. This nonparametric test was chosen as it allows the detection of differences in the distribution of values, determining if the tested samples come from the same population.

\section{Scanning electron microscopy}

Samples collected in the northern area during the summer of 2005 were processed for scanning electron microscopy (SEM). Specimens $(n=12)$ were fixed in $2.5 \%$ phosphate-buffered glutaraldehyde, dehydrated in an ethanol series, critical-point dried in $\mathrm{CO}_{2}$, mounted on specimen stubs using a fine coating of Araldite (i.e. epoxy) glue, sputter coated with gold-palladium to a thickness of $20-40 \mathrm{~nm}$ and examined at $5 \mathrm{kV}$. To examine their internal anatomy by SEM, specimens in $100 \%$ ethanol were cut transversally or held on their side between glass slides and cut longitudinally using a razor blade. Other specimens were freeze-fractured in liquid nitrogen after first being infiltrated with epon and placed in a gelatine capsule to help stabilize the specimens during the freeze-fracture process. Cut or fractured specimens were then prepared for SEM.

\section{Histology}

Three individuals exhibiting varying degrees of maturation, also collected in the northern region during the summer of 2005, were used for histological sectioning in order to elucidate the arrangement and development of the reproductive organs and eggs. Individuals were fixed in Bouin's fixative, embedded in liquid paraffin, sectioned at $5 \mu \mathrm{m}$ with a rotary microtome and stained with either haematoxylin and eosin or Periodic Acid Schiff (PAS) reagent. Specimens were then mounted in Entellan ${ }^{\text {TM }}$ (Merck) and observed using light microscopy.

\section{RESULTS}

\section{Comparative sequence analysis}

Totals of 21 lsrDNA and 22 ITS-2 sequences were obtained from the 24 individuals analysed; specimens collected in the south during summer (i.e. during the period with the highest temperatures) usually proved the least amenable to genetic analysis. Comparative sequence analysis showed 2 distinct genotypes for both the 1srDNA and ITS-2. In both cases, the more common genotype (hereafter designated 'common') was found throughout the year in the north and south, and only during spring in the central region, whereas the less common genotype (hereafter designated 'central') was found only in the central region from summer to winter. Within each genotype, no sequence variation was observed for either rDNA region.

Comparison of the lsrDNA sequences (1301 nucleotides) showed 18 transitional and 7 transversional substitutions $(\mathrm{ts} / \mathrm{tv}=2 \cdot 57)$, or a raw genetic distance of $1 \cdot 9 \%$. Comparison of the ITS-2 sequences (612 nucleotides) showed 10 transitional and 3 transversional changes $(\mathrm{ts} / \mathrm{tv}=3 \cdot 33)$, or a raw genetic distance of $2 \cdot 1 \%$. Comparisons of sequence 
Table 1. Comparison of genetic distances ( $\%$ difference) between spathebothridean taxa using large subunit rDNA (lsrDNA) and internal transcribed spacer 2 (ITS-2)

(Dip, Diplocotyle orikii; Cyt, Cyathocephalus truncatus; Dib:Com, Didymobothrium rudolphii 'common' genotype; Dib:Cen, Didymobothrium rudolphii 'central' genotype; Sps, Spathebothrium simplex.)

\begin{tabular}{|c|c|c|c|c|c|c|c|c|}
\hline \multirow[b]{2}{*}{ Taxon§ } & \multicolumn{4}{|c|}{ lsrDNA $(N=1275 \mathrm{bps})$} & \multicolumn{4}{|c|}{ ITS-2 $(N=588 \mathrm{bps})$} \\
\hline & Sps & Dip & Cyt & Dib:Com & Sps & Dip & Cyt & Dib:Com \\
\hline Dip & $5 \cdot 6$ & & & & $6 \cdot 1$ & & & \\
\hline Cyt & $6 \cdot 1$ & $4 \cdot 2$ & & & $7 \cdot 7$ & $4 \cdot 1$ & & \\
\hline Dib:Com & $7 \cdot 5$ & $7 \cdot 1$ & $6 \cdot 0$ & & $8 \cdot 7$ & $5 \cdot 4$ & $6 \cdot 9$ & \\
\hline Dib:Cen & $6 \cdot 4$ & $6 \cdot 3$ & $5 \cdot 3$ & $2 \cdot 0$ & $9 \cdot 5$ & $5 \cdot 9$ & $7 \cdot 4$ & $2 \cdot 2$ \\
\hline
\end{tabular}
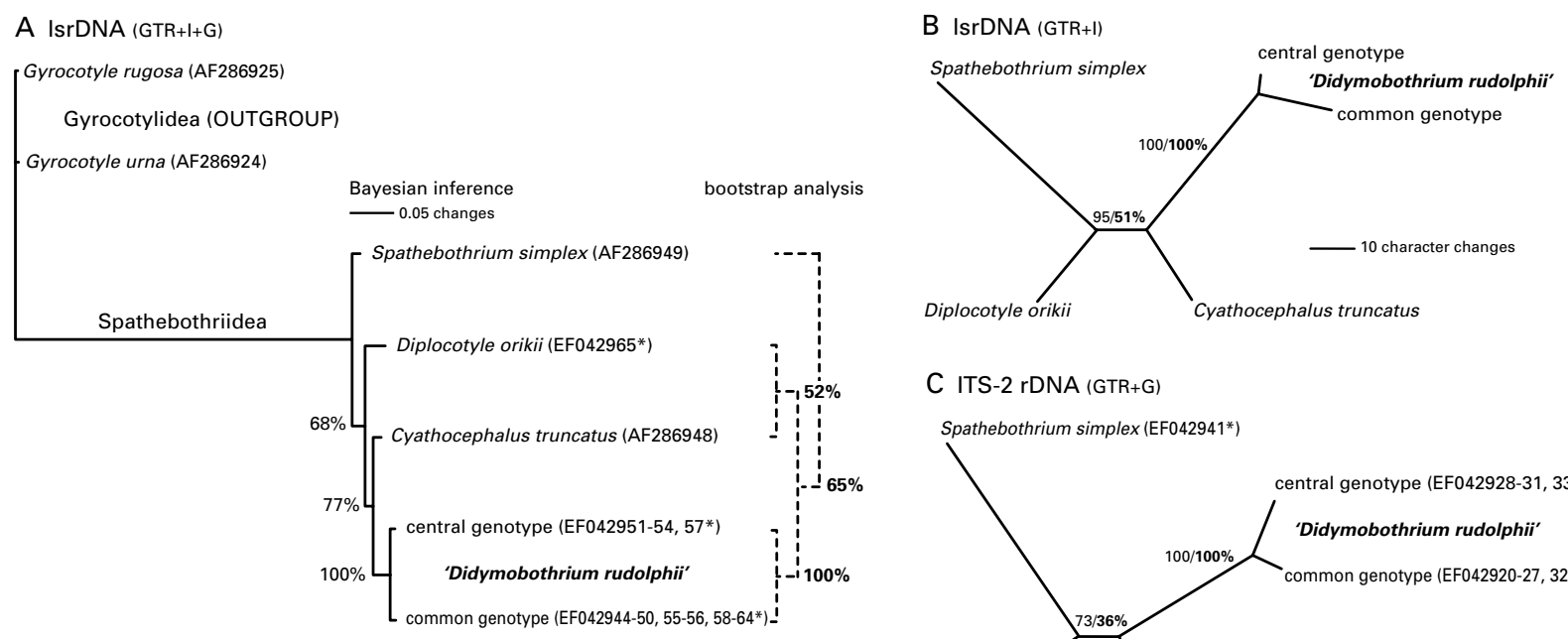

C ITS-2 rDNA (GTR+G)

Spathebothrium simplex (EF042941*)

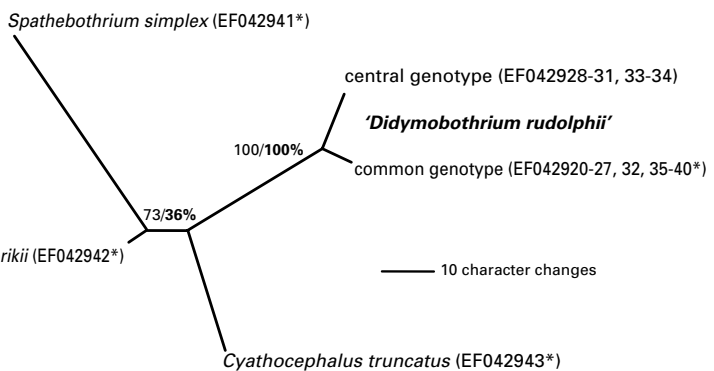

Fig. 2. Phylogenetic analyses of lsrDNA and ITS-2. (A) Rooted phylogram with relative branch lengths based on Bayesian inference (solid lines) and parsimony-based bootstrap analysis (dashed lines) of 888 bps of lsrDNA. (B) Unrooted phylograms based on 1275 bps of lsrDNA, and (C) on 588 bps ITS-2. Nodal support shown as posterior probabilities/bootstrap consensus (bold). GenBank sequence Accession numbers are shown parenthetically; those characterized in the present study are marked with an asterisk.

divergence between the 2 genotypes and other spathebothriidean genera showed Cyathocephalus to be most similar, with a raw distance of $5 \cdot 3 \%$ from the central genotype and $6 \%$ from the common genotype. Other distances estimated are given in Table 1.

\section{Phylogenetic analyses}

Phylogenetic analysis of the lsrDNA data, including those of gyrocotylidean outgroup taxa (Fig. 2A), showed Spathebothrium to be the sister of the other spathebothriidean taxa and that the common and central genotypes of Didymobothrium formed a clade with Cyathocephalus and represent its sister lineage. Although both Bayesian and parsimony-based bootstrap analyses supported Spathebothrium as the earliest diverging taxon, slight differences were seen in the interrelationships of the other spathebothriidean taxa, with nodal support being weak in both analyses. In the unrooted, individual analyses of 1srDNA and ITS-2 data sets (Fig. 2B and C), the 2 genotypes of Didymobothrium formed sister lineages with a high degree of divergence between them and, similarly, terminal branch lengths were long relative to the internal branch separating Spathebothrium + Diplocotyle from Cyathocephalus + the 2 Didymobothrium genotypes. Comparison of relative branch lengths between lsrDNA (Fig. 2B) and ITS-2 (Fig. 2C) showed lsrDNA data estimating slightly more equitable divergences between the lineages.

\section{Morphological analyses}

Morphometric comparison of the 'common' and 'central' genotypes of D. rudolphii as defined by the 
Table 2. Morphometric comparison of the 'common' and 'central' genotypes of Didymobothrium rudolphii and other species of the Acrobothriidae as available in the literature

(Values correspond to the mean \pm standard deviation and range (in parentheses) in $\mu \mathrm{m}$ (except where noted). * indicates significant differences between $D$. rudolphii genotypes $(P<0 \cdot 05)$. §TL, total length; MW, maximum width; TLsclx, total length of the scolex; MWsclx, maximum width of the scolex; MTsclx, maximum thickness of the scolex; DistPore, distance between two consecutive female genital pores; DistCirr, distance between two consecutive cirri; MDcirr, maximum diameter of the cirrus; Nprogs, number of proglottides; MDtestes, maximum diameter of testes; Ntestes, number of testes; MLegg, maximum length of eggs; MWegg, maximum width of eggs; MLut, maximum length of the uterus; MWut, maximum width of the uterus; MLov, maximum length of the ovary; MWov, maximum width of the ovary; MWvt, maximum width of the vitellarium; Prout, percentage of strobila width occupied by the uterus; Proov, percentage of strobila width occupied by the ovary; Provt, percentage of strobila width occupied by vitellaria.

(1) as 'Bothrimonus nylandicus' from Schneider, 1902

(2) Adapted from Burt and Sandeman, 1969

(3) Nybelin, 1922

(4) Renaud and Gabrion, 1988.)

\begin{tabular}{|c|c|c|c|c|c|c|c|}
\hline Variable§ & $\begin{array}{l}\text { Didymobothrium } \\
\text { rudolphii 'common } \\
\text { genotype' } \mathrm{N}=39\end{array}$ & $\begin{array}{l}\text { Didymobothrium } \\
\text { rudolphii 'central } \\
\text { genotype' } \mathrm{N}=14\end{array}$ & $\begin{array}{l}\text { Diplocotyle } \\
\text { nylandica } \\
\text { (1) }\end{array}$ & $\begin{array}{l}\text { Diplocotyle } \\
\text { olrikii } \\
\text { (2) }\end{array}$ & $\begin{array}{l}\text { Bothrimonus } \\
\text { fallax } \\
(3)\end{array}$ & $\begin{array}{l}\text { "Bothrimonus } \\
\text { sturionis" } \\
(2)\end{array}$ & $\begin{array}{l}\text { "Bothrimonus } \\
\text { nylandicus" } \\
(4)\end{array}$ \\
\hline $\mathrm{TL}(\mathrm{mm}) *$ & $\begin{array}{l}33 \cdot 9 \pm 18 \\
(10 \cdot 4-99 \cdot 2)\end{array}$ & $\begin{array}{l}51 \cdot 8 \pm 26 \cdot 7 \\
(16 \cdot 2-103 \cdot 6)\end{array}$ & $(5-20)$ & $(5-130)$ & $(20-170)$ & $(8-90)$ & $>20$ \\
\hline MW* & $\begin{array}{c}792 \pm 370 \\
(208-1800)\end{array}$ & $\begin{array}{c}642 \pm 238 \\
(217-1042)\end{array}$ & $(800-1000)$ & $(300-3000)$ & $(1500-4500)$ & $(400-2000)$ & $(690-710)$ \\
\hline TLsclx & $\begin{array}{r}513 \pm 120 \\
(279-737)\end{array}$ & $\begin{array}{r}507 \pm 134 \\
(357-789)\end{array}$ & & $(480-970)$ & 1500 & $(135-680)$ & \\
\hline MWsclx & $\begin{array}{r}616 \pm 149 \\
(389-853)\end{array}$ & $\begin{array}{c}623 \pm 266 \\
(463-1147)\end{array}$ & & $(570-2000)$ & $(1400-1500)$ & $(310-800)$ & \\
\hline MTsclx & $\begin{array}{r}608 \pm 165 \\
(155-863)\end{array}$ & $\begin{array}{c}605 \pm 176 \\
(421-863)\end{array}$ & & $(560-1550)$ & $(2000-2250)$ & $(390-1140)$ & \\
\hline DistPore* & $\begin{array}{c}500 \pm 246 \\
(205-1179)\end{array}$ & $\begin{array}{c}781 \pm 337 \\
(253-1474)\end{array}$ & & & & & \\
\hline DistCirr* & $\begin{array}{c}501 \pm 254 \\
(188-1263)\end{array}$ & $\begin{array}{c}735 \pm 356 \\
(212-1474)\end{array}$ & & & & & \\
\hline MDCirr & $\begin{array}{c}111 \pm 28 \\
(47-158)\end{array}$ & $\begin{array}{r}98 \pm 27 \\
(48-147)\end{array}$ & & $(125-230)$ & 300 & $(120-200)$ & \\
\hline Nprogs & $\begin{array}{r}78 \pm 38 \\
(27-183)\end{array}$ & $\begin{array}{r}75 \pm 25 \\
(42-130)\end{array}$ & $(15-30)$ & $(32-216)$ & $(400-500)$ & $(25-168)$ & $(40-65)$ \\
\hline Ntestes & $\begin{array}{r}28 \pm 6 \\
(12-40)\end{array}$ & $\begin{array}{r}28 \pm 8 \\
(20-42)\end{array}$ & & & & & \\
\hline MDtestes & $\begin{array}{r}93 \pm 20 \\
(53-128)\end{array}$ & $\begin{array}{r}87 \pm 15 \\
(63-116)\end{array}$ & & $(70-110)$ & $(100-190)$ & $(45-75)$ & 24 \\
\hline MLegg* & $\begin{array}{r}34 \pm 4 \\
(25-42)\end{array}$ & $\begin{array}{r}37 \pm 4 \\
(31-44)\end{array}$ & 40 & $(33-46)$ & $(35-41)$ & $(33-42)$ & $(30-34)$ \\
\hline MWegg* & $\begin{array}{r}18 \pm 2 \\
(14-22)\end{array}$ & $\begin{array}{r}20 \pm 2 \\
(16-23)\end{array}$ & $(25-30)$ & $(20-29)$ & $(27-31)$ & $(21-30)$ & 20 \\
\hline MLut & $\begin{array}{r}383 \pm 167 \\
(115-919)\end{array}$ & $\begin{array}{r}440 \pm 212 \\
(126-836)\end{array}$ & & & & & \\
\hline MWut* & $\begin{array}{r}473 \pm 182 \\
(175-916)\end{array}$ & $\begin{array}{r}379 \pm 130 \\
(140-533)\end{array}$ & & & & & \\
\hline MLov & $\begin{array}{c}312 \pm 132 \\
(81-660)\end{array}$ & $\begin{array}{c}308 \pm 97 \\
(203-470)\end{array}$ & & & & & \\
\hline MWov* & $\begin{array}{r}451 \pm 166 \\
(191-912)\end{array}$ & $\begin{array}{r}316 \pm 122 \\
(134-509)\end{array}$ & & & & & \\
\hline MWvt* & $\begin{array}{c}158 \pm 78 \\
(53-391)\end{array}$ & $\begin{array}{r}111 \pm 43 \\
(73-239)\end{array}$ & & & & & \\
\hline Prout (\%) & $\begin{array}{c}55 \pm 12 \\
(33-84)\end{array}$ & $\begin{array}{c}56 \pm 10 \\
(36-70)\end{array}$ & & & & & \\
\hline Proov (\%) & $\begin{array}{c}51 \pm 14 \\
(32-83)\end{array}$ & $\begin{array}{c}49 \pm 14 \\
(32-83)\end{array}$ & & & & & \\
\hline Provt (\%) & $\begin{array}{c}18 \pm 8 \\
(7-43)\end{array}$ & $\begin{array}{c}19 \pm 11 \\
(9-49)\end{array}$ & & 72 & 75 & $(46-55)$ & \\
\hline
\end{tabular}

molecular analyses, showed considerable overlap in the ranges of most characters, although the central genotype was generally greater in length and more slender on average. Indeed, significant differences $(P<0 \cdot 05)$ were found between the total length (TL), maximum width (MW), genital pore distances (PoreDist, CirrDist), egg mean width and length (MWegg, MLegg) and uterus, ovary and vitellarium mean width (MWut, MWov, MWvt, respectively) (Table 2). Morphometric comparisons also showed 

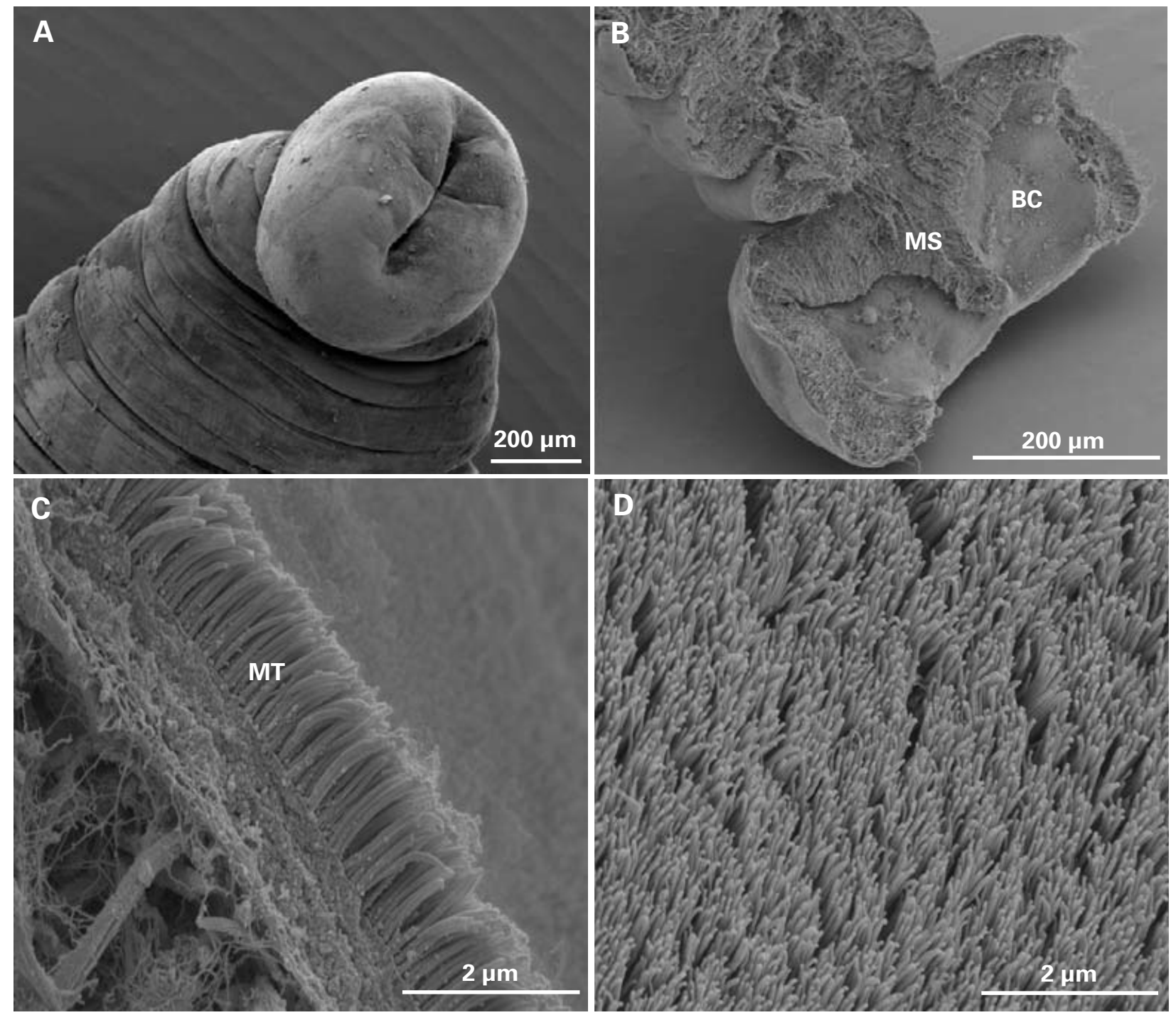

Fig. 3. Scanning electron micrographs of the scolex of Didymobothrium rudolphii collected from Solea lascaris along the Portuguese coast. (A) Apical view of the scolex showing the longitudinal opening. (B) Scanning electron micrograph of a longitudinal section of the scolex showing the median septum. (C) Microtriches in longitudinal section, covering the body cut in transverse section. (D) Microtriches covering the surface of the scolex. BC, bothrideal cavity; MS, median septum; MT, microtriches.

that most measurements and counts taken from both genotypes of D. rudolphii were within the range of those found for other Acrobothriidae (sensu Gibson, 1994), with the exception of those of Bothrimonus fallax Lühe, 1900 which were generally greater (Table 2). Minimum values in D. rudolphii (sensu lato) were generally lower than for those of Diplocotyle olvikii, but higher than those of 'Bothrimonus sturionis' Duvernoy, 1842 (actually a species of Diplocotyle (see Gibson, 1994)), particularly those of the scolex (Table 2). Although few records were found for D. nylandica, the measurements of this species differed most from those of Didymobothrium rudolphii. The range of egg measurements rarely overlapped with those of the other species, with the eggs of $D$. rudolphii being typically smaller (Table 2).
Morphology and ultrastructure of Didymobothrium rudolphii 'common' genotype

Most features described are the same for the 2 genotypes of D. rudolphii. However, where given, the measurements describe only the 'common' genotype to avoid conflation of the 2 cryptic entities (see Table 2 for the morphometrics of the 'central' genotype). Similarly, all histological and SEM studies were conducted on specimens representing the 'common' genotype as present in the northern region.

Body elongate, dorso-ventrally flattened, 10$99 \mathrm{~mm}$ in length, $0 \cdot 2-1.8 \mathrm{~mm}$ in width, with $\sim 78$ proglottides, most exhibiting the same degree of maturation. Scolex slightly rounded (Fig. 3A), comprising 2 strongly muscular, forwardly directed, hollow bothridia separated by complete septum 

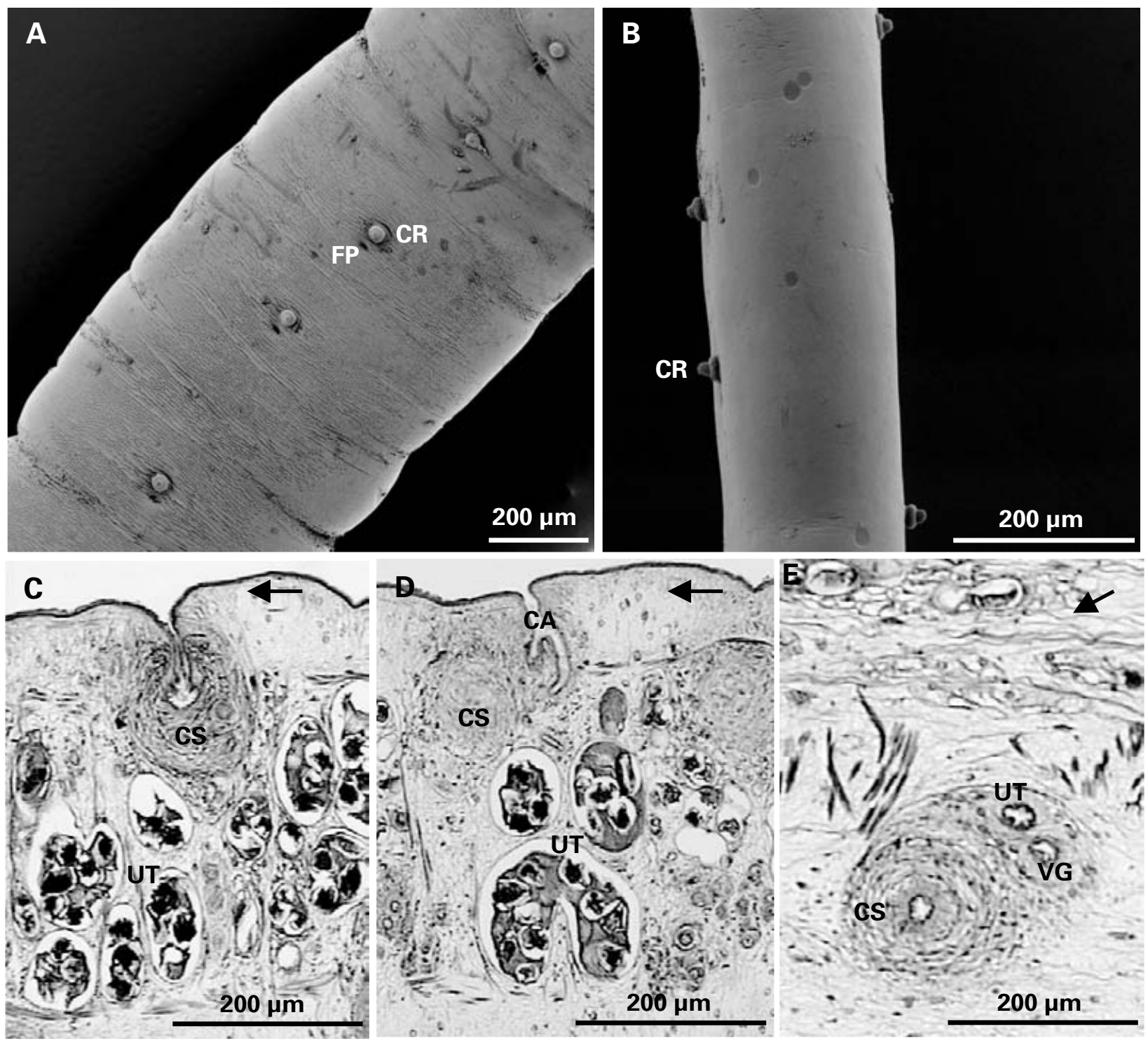

Fig. 4. Scanning electron micrographs and histological sections of the strobila of Didymobothrium rudolphii collected from Solea lascaris along the Portuguese coast. (A) Ventral view of the strobila. (B) Lateral view of the strobila showing the irregularly alternating pattern of genital pores. (C and D) Sagital sections showing the reproductive organs and their openings. (E) Longitudinal section showing the cirrus-sac, vagina and uterus. CA, common atrium; CR, cirrus; CS, cirrus-sac; FP, female pore; UT, uterus; VG, vagina. Arrow indicates the anterior end of the worm.

(Fig. 3B). (Live worms presented significant variation in scolex shape, appearing to have either 1 or 2 hollow bothridia due to the contraction or extension of the septum (see also Burt and Sandeman, 1969)). Entire body, including scolex and internal surface of bothridia, covered with short, filiform microtriches $\sim 2 \mu \mathrm{m}$ in length (Fig. $3 \mathrm{C}$ and D). Male and female genital pores open separately, in close proximity, along median line of strobila, most frequently on same side (Fig. 4A) but always irregularly alternating at some point in series (Fig. 4B). Male pore anterior to female pore; everted cirrus teat-like in shape (Fig. 4A and B), devoid of microtriches. Cirrus-sac ovoid (Fig. 4C); walls muscular (Fig. 4C and E). Female pore ovoid (Fig. 4A), with muscular common atrium into which vagina and uterus open sideby-side (Fig. 4D and E).
Proglottides exhibit same degree of maturation in most individuals (Figs 5A and 6A), but some worms presented less well-developed proglottides anteriorly (Figs 5B and 6B). Internal longitudinal musculature well developed, forming bundles between vitelline fields and medulla (Figs 5C and 6C). Vitellarium follicular and continuously distributed along margins of strobila (Figs 5D and 6A). Number of testes associated with each proglottis also varied (12-42) according to state of maturity. Vas deferens convoluted, often filled with spermatozoa, enters cirrussac forming ejaculatory duct (Fig. 5E). Vitellarium occupies $7-43 \%$ of body width depending on degree of maturation. Ovary medullary, lobulate (Fig. 5D), located posterior to uterus, occupies $32-83 \%$ of strobilar width, thin-walled, contains muscle fibres and glycogen (PAS-positive, diastase labile); when 


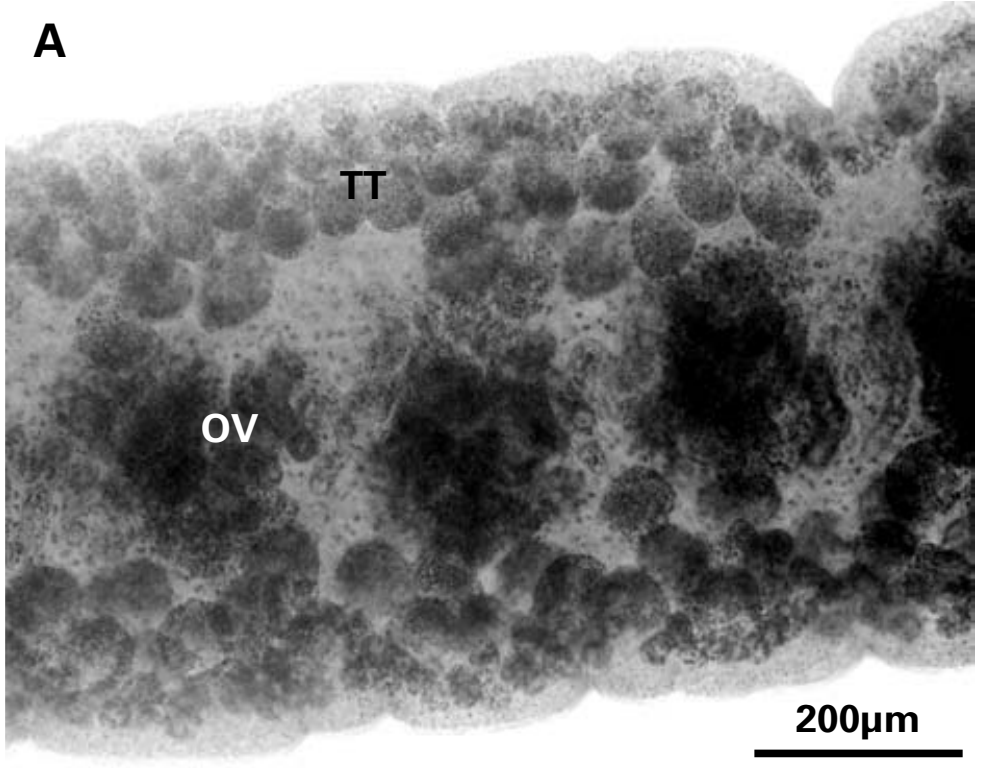

\section{B}
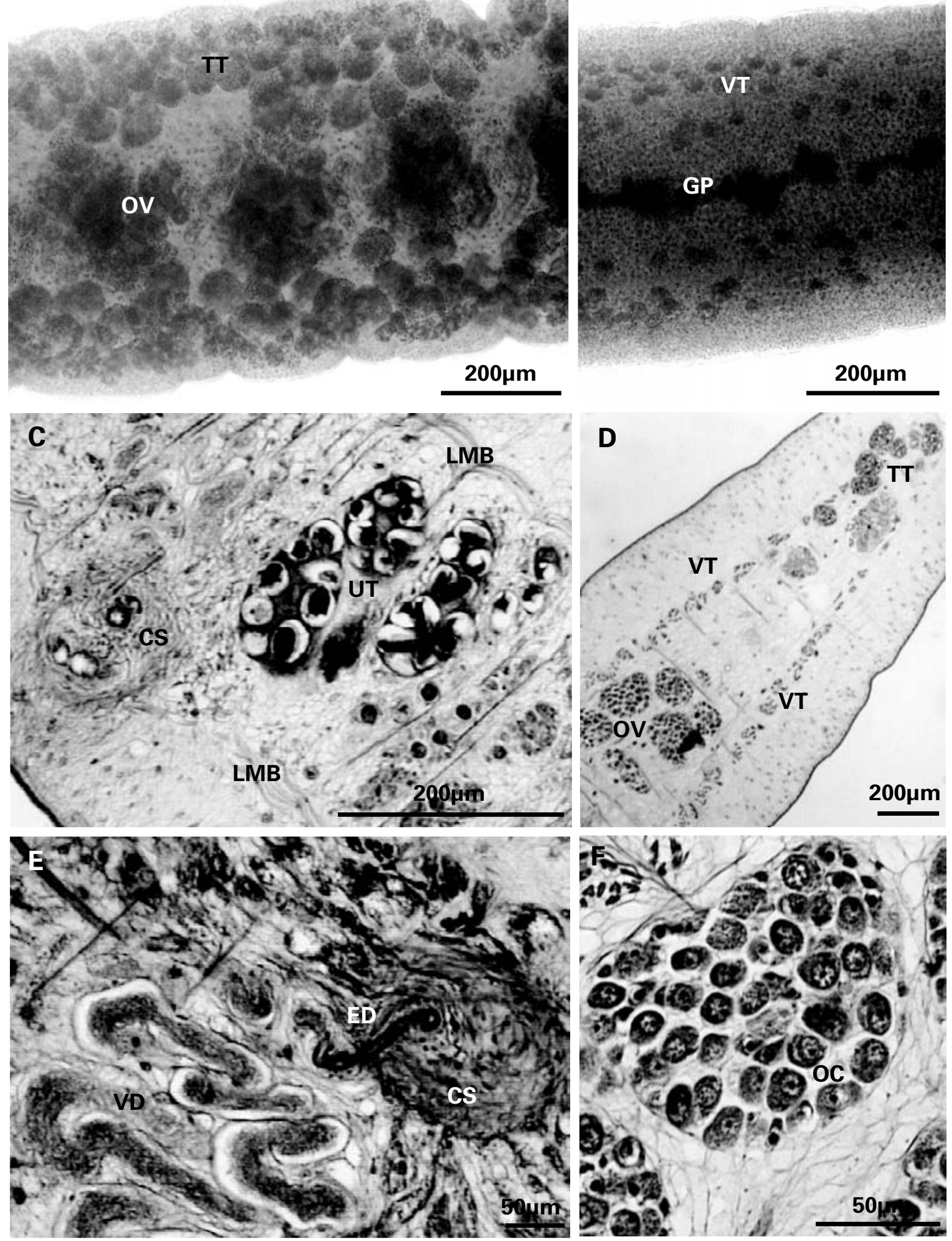

Fig. 5. Light micrographs and histological sections of the reproductive organs of Didymobothrium rudolphii. (A) Mature proglottides, (B) immature proglottides, (C) sagittal section showing longitudinal muscle fibres and reproductive organs (uterus, cirrus-sac). (D) Transverse section showing vitelline follicles, testes and ovary, (E) male genital apparatus, and (F) mature ovary. CS, cirrus-sac; ED, ejaculatory duct; GP, genital primordial; LMB, longitudinal muscle bundles; OC, oocytes; OV, ovary; TT, testis; UT, uterus; VD, vas deferens; VT, vitelline follicles. 
A

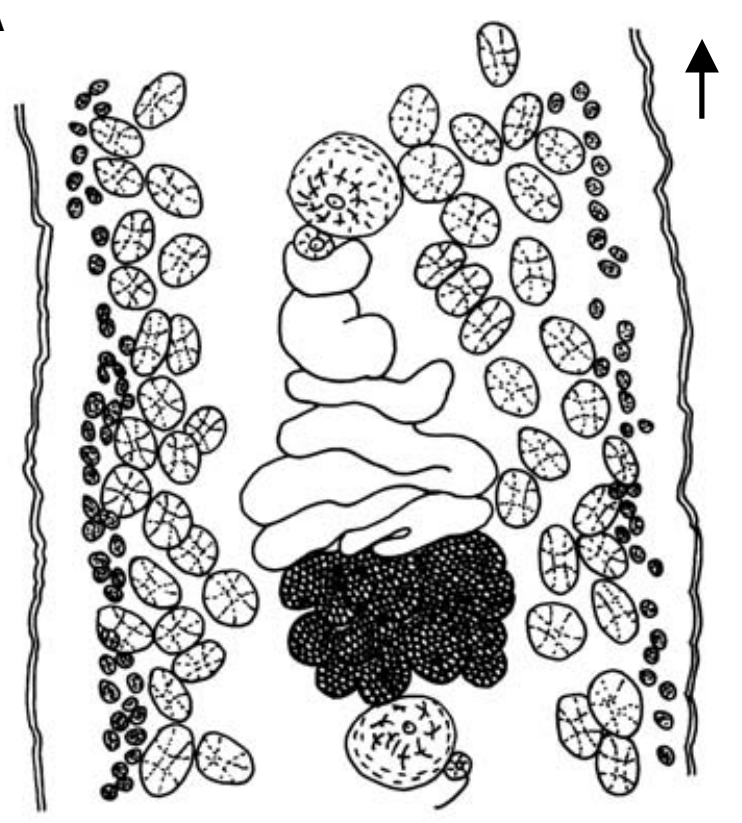

$200 \mu \mathrm{m}$
B



C

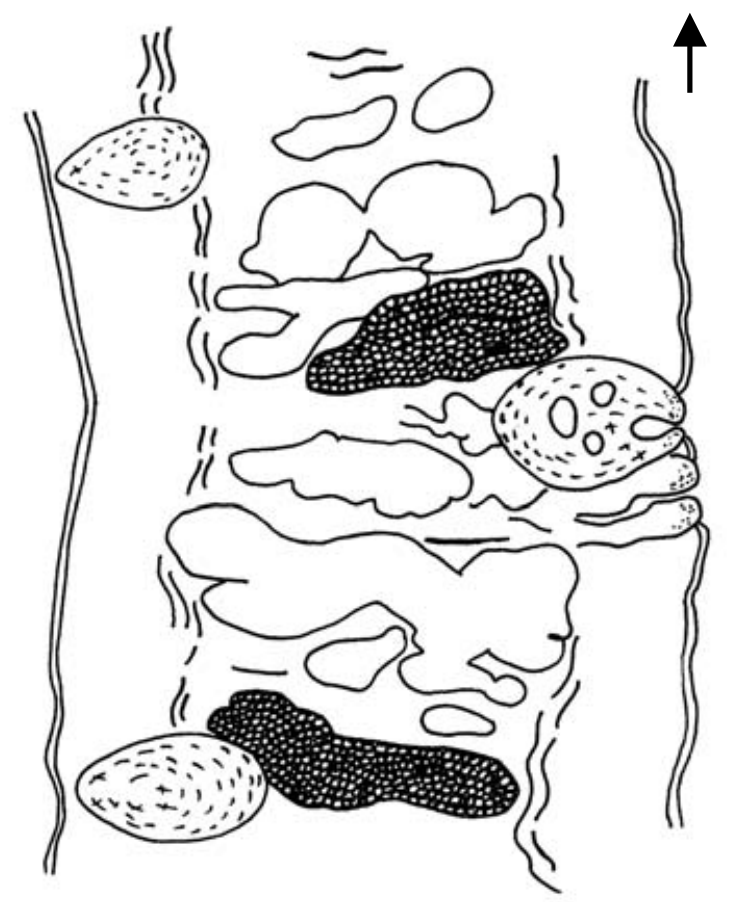

$200 \mu \mathrm{m}$

Fig. 6. Strobila of Didymobothrium rudolphii. (A) Mature region, (B) immature region, (C) longitudinal section showing muscle fibres and reproductive organs (uterus, ovary, cirrus-sac, testes). Arrow indicates the anterior end of the worm.

mature, all oocytes appear to be at similar stage of development (Fig. 5F).

Uterus tubular, convoluted (Fig. 7A), packed with eggs at varying degrees of maturity throughout its length (Fig. 7B-D); uterine field extends over $33-84 \%$ of strobilar width and overlaps ovary. Proximal uterus filled with oocytes surrounded by thin, translucent shell, whereas eggs in middle and distal regions have glycogenic (PAS-positive, diastase labile) envelope (Fig. 7C); oblong eggs within most distal region of uterus have fully-developed tanned shells, including tuft of filaments at narrow pole (Fig. 7D-F) resembling 'spaghetti' (Fig. 7F) and containing glycogen (PAS-positive, diastase 

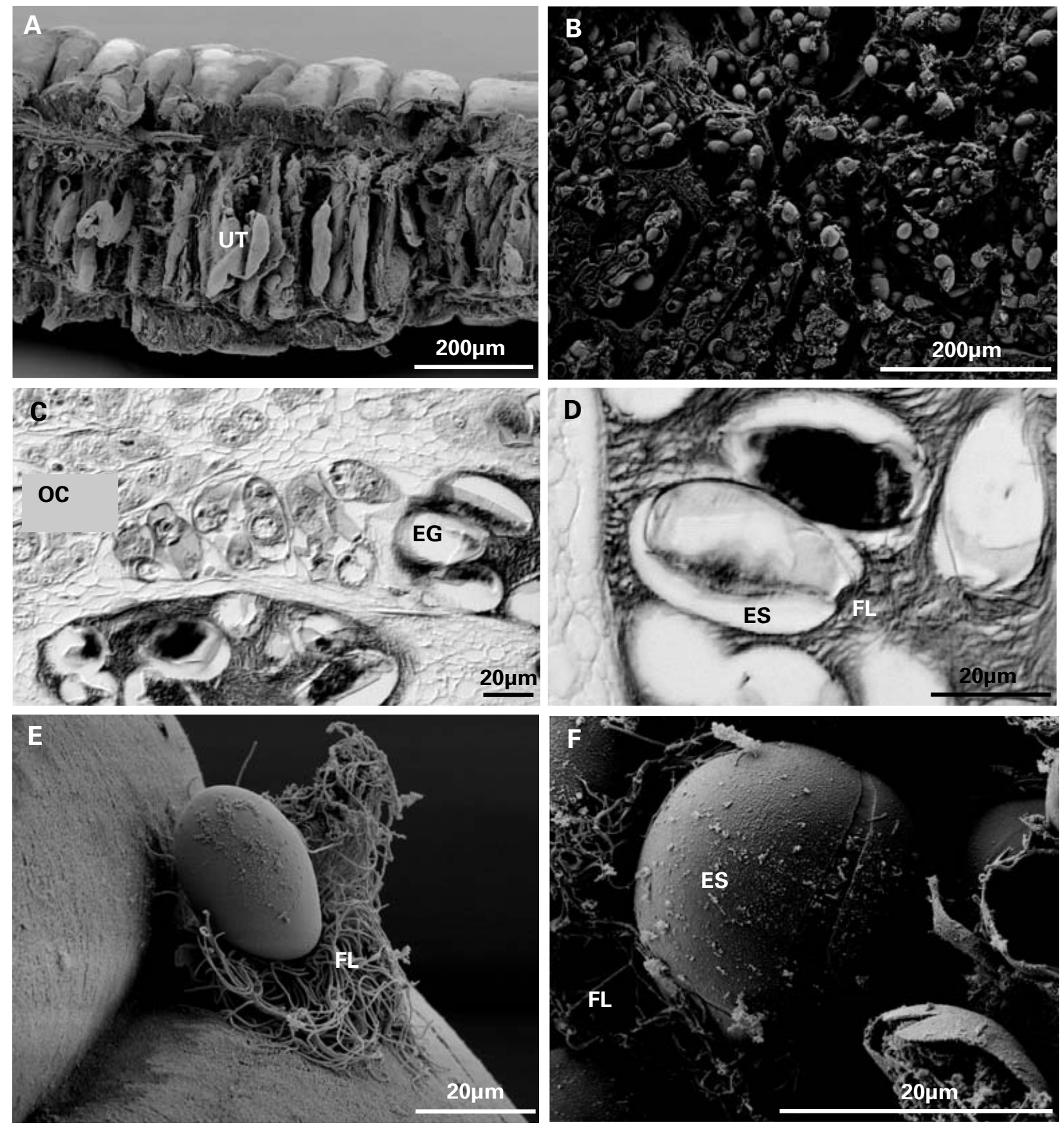

Fig. 7. Scanning electron micrographs and histological sections of the uterus and eggs of Didymobothrium rudolphii collected from Solea lascaris along the Portuguese coast. (A) Sagittal section of the strobila showing the uterine shape, (B) section of the uterus filled with eggs, (C) different stages of oocytes and eggs along the ovary, (D) eggs surrounded by a mucous envelope and glycogen filaments, (E) egg outside attached to the individual's body, and (F) egg-shell. EG, egg; ES, egg-shell; FL, glycogen filaments; OC, oocytes; UT, uterus.

labile) which are expelled with the eggs (Fig. 7E). Eggs $25-42 \mu \mathrm{m}$ in length, 14-22 $\mu \mathrm{m}$ in width; SEM revealed their rough surface $(\mathrm{Fig} .7 \mathrm{~F})$.

\section{Statistical analyses}

According to the PCA ordination diagram (Fig. 8), some degree of morphological differentiation consistent with that of genetic differentiation was found along the Portuguese coast, with most samples from the north and south ( $\mathrm{N}$ and $\mathrm{S}$ ) appearing on the lower half of the diagram and those from the centre (C) on the upper part of the diagram. Variables representing the major contribution to this pattern were the maximum width of the strobila (MW) and the distances between the genital pores (DistCirr, DistPore), although those associated with the scolex length, width and thickness (TLsclx, MWsclx and MTsclx, respectively), and those associated with the 


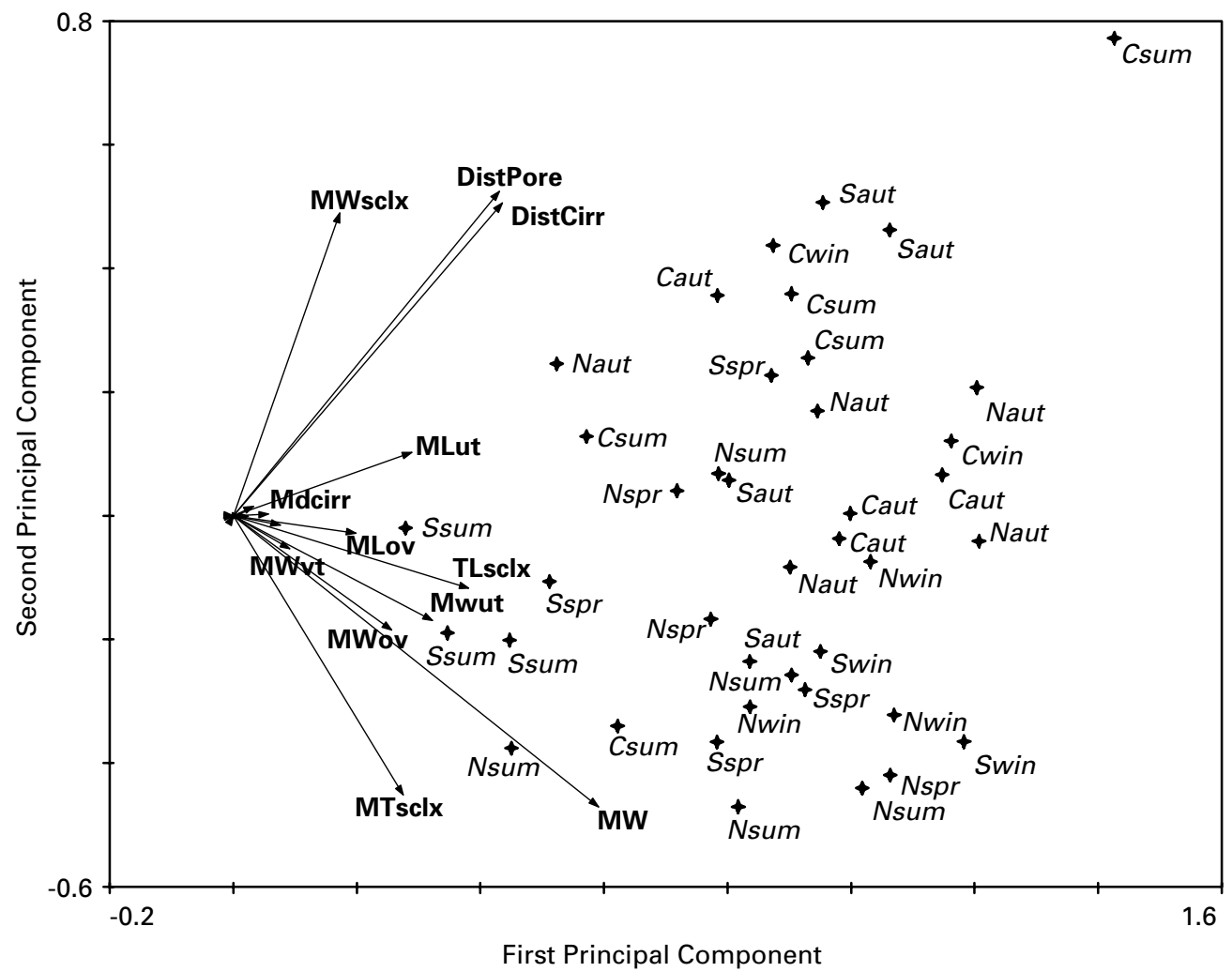

Fig. 8. Distribution of Didymobothrium rudolphii samples collected from Solea lascaris along the Portuguese coast in the space defined by the first two principal components obtained from the analysis of morphological characters. Sample abbreviations are defined according to their location and season as follows: $\mathrm{N}$, north; $\mathrm{C}$, centre; S, south; win, winter; spr, spring; sum, summer; aut, autumn. Only the most important variables contributing to the observed pattern are displayed: DistCirr, distance between two consecutive cirri; DistPore, distance between two consecutive female genital pores; MLov and MWov, maximum length and width of the ovary, respectively; MLut and MWut, maximum length and width of the uterus, respectively; MTsclx, maximum thickness of the scolex; MW, maximum width; MWsclx, maximum width of the scolex; MWvt, maximum width of the vitellarium; TL, total length; TLsclx, total length of the scolex.

shape of the uterus (MLut, MWut) and ovary width (MWov) were also important (Fig. 8). These results indicated that individuals from the centre were generally more slender than those form the north and south. They also presented a generally larger distance between their genital pores, which was also supported by the length of the uterus.

These results were in agreement with the significant differences found between measurements of the individuals presenting the 'common' and 'central' genotype (Table 2). The Kruskal-Wallis test, applied to the most important variables defining the pattern found in the PCA diagram, revealed significant differences in the distances between the genital pores according to season $(H>8.78$, $P<0.05)$ and in the total length of the scolex and mean width of the ovary according to locality $(H>6 \cdot 73, P<0 \cdot 05)$.

\section{Seasonal occurrence of D. rudolphii (sensu lato)}

Both mature and gravid specimens were found throughout the year, albeit gravid specimens were more frequent in the spring and summer. Although no overall seasonal pattern of the mean intensity of $D$. rudolphii infecting $S$. lascaris along the Portuguese coast was found, each region presented a different general trend (Fig. 9). Whereas in the northern region values decreased from winter to summer, increasing again towards autumn, in the central region values were more or less stable throughout the year, the highest being reported in summer, and in the southern region mean intensity increased from spring to autumn decreasing again during winter. These patterns of variation showed some consistency with the pattern of variation of the most important items in the diet of $S$. lascaris within each region-Amphipoda (Fig. 9; open squares) in the north and south and Mysidacea (Fig. 9; filled circles) in the centre.

\section{Stomach contents of Solea lascaris}

The diet of $S$. lascaris consisted mainly of small Crustacea such as Amphipoda and Mysidacea, although Polychaeta and Bivalvia were also 



Fig. 9. Seasonal variation in the mean intensity of Didymobothrium rudolphii (sensu lato) (bars) and the number of prey items found in the stomach contents of Solea lascaris (lines) for the 3 areas off the Portuguese coast sampled. Prey number was log transformed due to scaling constraints. Abbreviations: AmpN, number of Amphipoda; BivN, number of Bivalvia; CumN, number of Cumacea; DecN, number of Decapoda; DrudI, D. rudolphii mean intensity; MysN, number of Mysidacea; PolN, number of Polychaeta.

important components (Fig. 9). When the diet was analysed according to season and locality by means of a multivariate correspondence analysis, using the number or weight of the different prey groups, the Mysidacea was the most important group in the diet in the central region during summer and autumn. On the other hand, during spring in the central region and in the northern and southern regions throughout the year, Amphipoda and Bivalvia were more important (A. M. Pinheiro, personal communication).

\section{DISCUSSION}

Molecular sequence analyses readily differentiated 2 distinct entities of Didymobothrium, corroborating the earlier findings of Renaud and Gabrion (1988) based on allozyme data. Although no 'molecular yardstick' has yet been calculated to delineate taxonomic entities of different rank in the Cestoda (and may, in any case, prove to be of limited validity in isolation of other data), the degree of sequence divergence between the 'common' and 'central' 
genotypes is considerable and easily in the range of that predicted for different species of the same genus (i.e. $1 \cdot 9-2 \cdot 1 \%$ ). Within the Digenea, for example, ITS sequence divergences of $2-3 \%$ have been shown to correlate well with morphological differences used to circumscribe congeners by traditional means (Nolan and Cribb, 2005).

Generally, the external morphology of D. rudolphii described here is in agreement with that reported in the original description of this species by Monticelli (1890) and its subsequent redescriptions (Monticelli, 1892; Nybelin, 1922), especially with regard to the morphology of the bothridea and everted cirrus, the lack of external segmentation and the irregularly alternating genital pores. The present work provides the first description of aspects of the internal anatomy and egg shape of D. rudolphii, thus contributing to a better understanding of its likely life-cycle. For example, the finding of polar filaments on the eggs, together with its rough surface, suggests that they may have the facility of attachment, thus assisting transfer to the intermediate host.

The comparison of the morphological data for D. rudolphii with those from the better studied Diplocotyle nylandica and D. olvikii (see MacKinnon and Burt, 1984; Brunanska et al. 2005 ; Poddubnaya et al. 2005) and those from Bothrimonus spp., in conjunction with the genetic data, has shown that Didymobothrium can be differentiated from the other spathebothriideans, thus at least partly corroborating the systematic classification presented by Gibson (1994).

Although we cannot rule out sampling error given the small number of samples sequenced (i.e. 2 per season per area), the lack of co-occurrence of the 2 genotypes during the same season (despite being sympatric with regard to the central locality) is in stark contrast to the findings of Renaud and Gabrion (1988), who found the 2 forms to co-occur. They suggested that the sympatric existence of 2 species could be explained by differences in intermediate (presumably amphipod) host usage. Whereas one species of Didymobothrium (which they referred to as Bothrimonus) utilized an intermediate host species present throughout the year, the other utilized another, only present in spring and summer, overwintering in the egg stage. This life-cycle is similar to that described by Sandeman and Burt (1972) for 'B. sturionis' (actually Diplocoytle (see Gibson, 1994)). Although such ecological niche separation could account for the divergence, it does not in itself explain why the 'common' form is absent for most of the year in the central region, while being present throughout the year in the north and south. This pattern requires one of a number of different potential isolating mechanisms: a method of active exclusion of the 'common' form by the 'central' form in the definitive host; a seasonal and ecological exclusion or exchange of intermediate host species occurring in the central region only; or an extreme feeding preference of Solea lascaris for a particular species of intermediate host when available in the environment. As for most of the Soleidae, S. lascaris feeds on a wide range of small invertebrates, their importance in the diet being defined by their abundance in the environment (Link et al. 2005). The composition and seasonal variation of $S$. lascaris diet along the Portuguese coast found in this study, supported by findings of other investigations (Cabral et al. 2002; A. M. Pinheiro, unpublished data), revealed a preference for feeding on Mysidacea during summer and autumn in the central region, whereas Amphipoda were preferred in all other regions and seasons sampled. The finding of a change in diet concordant with the occurrence of D. rudolphii specimens presenting different genotypes suggests that Mysidacea could act as the intermediate host of the 'central' form of D. rudolphii. Moreover, mean intensity values during these seasons were the highest in the central region, whereas the lowest value was recorded when the consumption of Amphipoda was much higher. Thus, some ecological host switching might have occurred in the life-cycle of $D$. rudolphii in the central region off the Portuguese coast, either due to environmental pressure that might have diminished the availability of the original host (Amphipoda), or to the ecological pressure exerted by the feeding preferences of S. lascaris.

The existence of cryptic species of cestodes infecting Pleuronectiformes off the Portuguese coast may not be entirely unusual, as they have also been reported in the pseudophyllidean Bothriocephalus scorpii (Müller, 1776) (Renaud et al. 1986; Verneau et al. 1997). The 2 species of this complex, B. renaudii Ortega and Valero, 1989 and B. gregarius Renaud, Gabrion and Pasteur, 1983, parasitizing turbot, Scophthalmus maximus, have a disjunctive distribution $-B$. renaudii occurring in the Atlantic Ocean, including off the western Portuguese coast, and $B$. gregarius off the southern Portuguese coast and in the Mediterranean Sea, English Channel, Baltic Sea and North Sea (Renaud et al. 1986). Although the life-cycle of Didymobothrium is unlikely to be the same as that for Bothriocephalus spp., something in the behaviour of the definitive host may facilitate the formation of sibling species in cestodes that utilize these fish hosts.

Although the present data are sufficient to circumscribe 2 different species of Didymobothrium using molecular characters, a morphological diagnosis remains tenuous at best, and we are reluctant to make nomenclatural changes on the basis of DNA alone. However, the results of the morphological analyses suggest that species may be differentiated by their overall size, or length to width ratio, and that future studies guided by these results may show this to be a reliable character. More sampling needs to be 
done in the central region in order to understand better how these entities remain sympatric but do not overlap in time or in the host infrapopulation, and to rule out the possibility that a sampling error has biased such conclusions. Elucidation of their lifecycles, presumed to involve amphipods and/or mysidaceans, could assist in explaining the speciation process.

This study was financed in part by the Fundação para a Ciência e a Tecnologia (FCT) through grants to J.F.M. (SFRH/BD/8983/2002) and M.J.S. (Grant SFRH/ BSAB/492/2005), and by the Treaty of Windsor Programme 2005-06 (LIS/992/2). The authors thank M. Helena Sousa (Universidade do Porto, Portugal) for assistance with the histology, and A. Ball (NHM) and C.P. Santos (Instituto Oswaldo Cruz) for assistance with the SEM, including expert guidance to P.D.O. on freezefracture methods. P.D. O. thanks R. Kuchta and H. Brabec (University of South Bohemia, Czech Republic) and A. Shinn (University of Stirling, Scotland) for assistance with the collection of Diplocotyle olrikii, and T. Scholz (University of South Bohemia, Czech Republic) for providing ethanol-fixed samples of Cyathocephalus. The authors also thank C. Griffin (NHM) for assistance with sequencing problematic samples and E. Sherlock (NHM) for preparation of the molecular voucher specimens. Finally we thank the anonymous reviewers for their helpful comments.

\section{REFERENCES}

Agustí, C., Aznar, F. J., Olson, P. D., Littlewood, D. T. J., Kostadinova, A. and Raga, J. A. (2005). Morphological and molecular characterization of tetraphyllidean merocercoids (Platyhleminthes: Cestoda) of striped dolphins (Stenella coeruleoalba) from the western Mediterranean. Parasitology 130, 461-474.

Aznar, F. J., Agustí, C., Littlewood, D. T. J., Raga, J. A. and Olson, P. D. (2007). The role of cetaceans in the tetraphyllidean life cycle: molecular and ecological data from the western Mediterranean. International Fournal for Parasitology 37, 243-255.

Brickle, P.., Olson, P. D., Littlewood, D. T. J., Bishop, A. and Arkhipkin, A. (2001). Parasites of Loligo gahi from waters off the Falkland Islands with a molecular-based identification of their cestode larvae. Canadian Fournal of Zoology 79, 2289-2296.

Brunanska, M., Poddubnaya, L. G. and Dezfuli, B. S. (2005). Vitellogenesis in two spathebothriidean cestodes. Parasitology Research 96, 390-397.

Burt, M. D. B. and Sandeman, I. M. (1969). Biology of Bothrimonus (=Diplocotyle) (Pseudophyllidea: Cestoda) Part I. History, description, synonymy, and systematics. Fournal of the Fisheries Research Board of Canada 26, 975-996.

Cabral, H. N., Lopes, M. and Loeper, R. (2002). Trophic niche overlap between flatfishes in a nursery area in the Portuguese coast. Scientia Marina 66, 293-300.

Davydov, V. G., Poddubnaya, L. G. and Kuperman, B. I. (1997). An ultrastructure of some systems of the Diplocotyle olvikii (Cestoda: Cyathocephalata) in relation to peculiarities of its life cycle. Parazitologiya 31, 132-141. (In Russian.)
Georgiev, B., Biserkov, V. and Genov, T. (1986). In toto staining method for cestodes with iron acetocarmine. Helminthologia 23, 279-281.

Gibson, D. I. (1994). Order Spathebothriidea Wardle and McLeod, 1952. In Keys to the Cestode Parasites of Vertebrates (ed. Khalil, L. F., Jones, A. and Bray, R. A.), pp. 15-19. CAB International, Wallingford.

Gibson, D. I. and Valtonen, E. T. (1983). Two interesting records of tapeworms from Finnish fishes. Aquilo, Ser. Zoologica 22, 45-49.

Hanzelová, V., Kuchta, R., Scholz, T. and Shinn, A. P. (2005). Morphometric analysis of four species of Eubothrium (Cestoda: Pseudophyllidea) parasites of salmonid fish: an interspecific and intraspecific comparison. Parasitology International 54, 207-214.

Infante, C., Catanese, G. and Manchado, M. (2004). Phylogenetic relationships among ten sole species (Soleidae, Pleuronectiformes) from the Gulf of Cádiz (Spain) based on mitochondrial DNA sequences. Marine Biotechnology 6, 612-624.

Link, J. S., Fogarty, M. J. and Langton, R. W. (2005). The trophic ecology of flatfishes. In Flatfishes Biology and Exploitation (ed. Gibson, R. N.), pp. 185-212. Blackwell Publishing, Oxford.

Mackiewicz, J. S. (2003). Caryophyllidea (Cestoidea): molecules, morphology and evolution. Acta Parasitologica 48, 143-154.

MacKinnon, B. M. and Burt, M. D. B. (1984). The comparative ultrastructure of spermatozoa from Bothrimonus sturionis Duv. 1842 (Pseudophyllidae) Pseudanthobothrium hanseni Baer, 1956 (Tetraphyllidae), and Monoecocestus americanus Stiles, 1895 (Cyclophyllidea). Canadian Fournal of Zoology 62, 1059-1066.

Maddison, W. P. and Maddison, D. R. (2005). MacClade: Analysis of Phylogeny and Character Evolution. Sinauer Associates, Sunderland, Massachusetts.

McGinnis, S. and Madden, T. L. (2004). BLAST: at the core of powerful and diverse set of sequence analysis tools. Nucleic Acids Research 32, W20-W25.

Monticelli, S. (1890). Note helminthologiche. Bollettino Società Naturalisti di Napoli 4, 189-208.

Monticelli, S. (1892). Sul genere Bothrimonus, Duvernoy e proposte per una classificazione dei Cestodi. Monitore Zoologico Italiano 5, 100-108.

Nolan, M. and Cribb, T. H. (2005). The use and implications of ribosomal DNA sequencing for the discrimination of digenean species. Advances in Parasitology 60, 102-156.

Nybelin, O. N. (1922). Anatomisch-systematische Studien über Pseudophyllideen. Göteborgs Kungl, Vetenskaps-och Vitterhets-Samhälles Handlingar, Fjärde-Följden 26, 1-228.

Nylander, J. A. A. (2004). MrModelTest, program distributed by the author. Evolutionary Biology, Uppsala University, Sweden.

Okaka, C. E. (2000). Maturity of the procercoid of Cyathocephalus truncatus (Eucestoda: Spathebothriidae) in Gammarus pulex (Crustacea: Amphipoda) and the tapeworms life cycle using the amphipod as the sole host. Helminthologia 37, 153-157.

Olson, P. D., Cribb, T. H., Tkach, V. V., Bray, R. A. and Littlewood, D. T. J. (2003). Phylogeny and 
classification of the Digenea (Platyhelminthes: Trematoda). International Fournal for Parasitology 33, 733-755.

Olson, P. D., Littlewood, D. T. J., Griffiths, D., Kennedy, C. R. and Arme, C. (2002). Evidence for the co-existence of separate strains or species of Ligula in Lough Neagh, Northern Ireland. Fournal of Helminthology 76, 171-174.

Olson, P. D., Littlewood, D. T. J., Bray, R. A. and Mariaux, J. (2001). Interrelationships and evolution of the tapeworms (Platyhelminthes: Cestoda). Molecular Phylogenetics and Evolution 19, 443-467.

Olson, P. D. and Tkach, V. V. (2005). Advances and trends in the molecular systematics of the parasitic Platyhelminthes. Advances in Parasitology 60, 165-243.

Pertierra, A. A. G. (2002). Redescription of Proteocephalus bagri and P. rhamdiae (Cestoda: Proteocephalidea), parasites of Ramdia quelen (Siluriformes: Pimelodidae) from South America, with comments on morphological variation. Folia Parasitologica 49, 55-66.

Poddubnaya, L. G., Mackiewicz, J. S. and Kuperman, B. I. (2003). Ultrastructure of Archigetes sieboldi (Cestoda: Caryophyllidea) : relationship between progenesis, development and evolution. Folia Parasitologica 50, 275-292.

Poddubnaya, L. G., Mackiewicz, J. S., Brunanska, M. and Scholz, T. (2005). Ultrastructural studies on the reproductive system of progenetic Diplocotyle olrikii (Cestoda, Spathebothriidea): Ovarian tissue. Acta Parasitologica 50, 199-207.

Poddubnaya, L. G., Gibson, D. I., Swiderski, Z. and Olson, P. D. (2006). Vitellocyte ultrastructure in the cestode Didymobothrium rudolphii (Monticelli, 1890): possible evidence for the recognition of divergent taxa within the Spathebothriidea. Acta Parasitologica 51, 255-263.

Posada, D. and Crandall, K. A. (1998). Modeltest: testing the model of DNA substitution. Bioinformatics 14, 817-818.

Protasova, E. N. and Roytman, V. A. (1995).

[Cyathocephalates, tapeworm helminths of marine and freshwater fish (Cestoda: Pseudophyllidea:

Cyathocephalata).] Osnovy Tsestodologii, Vol. 12.

Institute of Parasitology, Russian Academy of Sciences, Moscow.

Renaud, F. and Gabrion, C. (1988). Speciation in Cestoda: evidence for two sibling species in the complex Bothrimonus nylandicus (Schneider 1902) (Cestoda: Cyathocephalidae). Parasitology 97, 139-147.

Renaud, F., Gabrion, C. and Pasteur, N. (1986). Geographical divergence in Bothriocephalus (Cestoda) of fishes demonstrated by enzyme electrophoresis. International Fournal for Parasitology 16, 553-558.

Reyda, F. B. and Olson, P. D. (2003). Cestodes of cestodes of Peruvian freshwater stingrays. Fournal of Parasitology 89, 1018-1024.

Ronquist, F. and Huelsenbeck, J. (2003). MRBAYES 3 : Bayesian phylogenetic inference under mixed models. Bioinformatics 19, 1572-1574.

Sandeman, I. M. and Burt, M. D. B. (1972). Biology of Bothrimonus (=Diplocotyle) (Pseudophyllidea: Cestoda): ecology, life cycle, and evolution; a review and synthesis. Fournal of Fisheries Research Board of Canada 29, 1381-1395.

Schneider, G. (1902). Bothrimonus nylandicus n. sp. Archiv für Naturgeschichte 1, 72-78.

Swofford, D. L. (2001). PAUP*. Phylogenetic Analysis Using Parsimony (*and other Methods). Version 4. Sinauer Associates, Massachusetts.

SPSS 13.0 (2004). SPSS Inc., Chicago.

ter Braak, C. J. F. and Smilauer, P. (2002). Canoco for Windows Version 4.5. Biometris - Plant Research International, Wageningen, The Netherlands.

Verneau, O., Renaud, F. and Catzeflis, F. (1997). Evolutionary relationships of sibling tapeworm species (Cestoda) parasitizing teleost fishes. Molecular Biology and Evolution 14, 630-636.

Zehnder, M. P. and de Chambrier, A. (2000). Morphological and molecular analyses of the genera Peltidocotyle Diesing, 1850 and Othinoscolex Woodland, 1933, and morphological study of Woodlandiella Freze, 1965 (Eucestoda, Proteocephalidea), parasites of South American siluriform fishes (Pimelodidae). Systematic Parasitology 46, 33-43. 